\title{
Utility Comparison of Chest Lateral Decubitus Projection with AP and PA Position
}

\author{
Guirack Choi \\ Dept. of Radiology, Nambu University

\section{흥부 측와위 촬영 시 전후방향과 후전방향 검사의 유용성 비교} \\ 최규락 \\ 남부대학교 방사선학과
}

\begin{abstract}
Chest lateral decubitus radiation exposure PA be carried out in general, but emergency patient or the patient's discomfort in the body examination had a lot of inconvenience. In this study, we compared AP and PA image quality, patient safety, and analysis of the examination effectiveness between the two tests was to evaluate the usefulness. Pleurisy or pneumothorax in patients with suspected or diagnosed chest lateral decubitus radiation exposure 30 consecutive patients (male 20 patients, 10 females) were included in the study. Image quality evaluation method microstructure of lung, wide areas of diagnosis, a clear air-fluid interface, the patient rotate, cardiac shadow and sharp diaphragmatic was based on Department of Radiology specialist, division of pulmonology resident blind test was evaluated by four people. Chest decubitus by radiation exposure the $\mathrm{AP}$ and $\mathrm{PA}$ position examination the usefulness of comparative analysis Image quality in the $\mathrm{AP}$ and $\mathrm{PA}$, whereas there was no significant difference in attitude, Stability of the patient and Radiation's examination efficiency AP position compared to the position of PA scores were higher. PA position does not require a examination may be of $\mathrm{AP}$ position in a position to suggest that.
\end{abstract}

Keyword : Chest lateral decubitus, AP position, PA position

\section{요 약}

Chest lateral decubitus 촬영은 일반적으로 PA 검사를 시행하여 왔으나, 응급환자나 몸이 불편한 환자의 검사에 있어 많은 불편이 있었다. 이에 본 연구에서는 $\mathrm{AP}$ 검사와 $\mathrm{PA}$ 검사를 비교하여 영상의 질, 환자의 안전성, 검사 효율성을 분석하고 두 검사간의 유용성을 알아보고자 하였다. 본원에서 2011.10.1 2012.7.30 까지 늑막염 또는 기흉으로 의심되거나 진단된 환자들 중 chest lateral decubitus 촬영을 시행한 30명(남자 20 명, 여자 10명)을 대상으로 하였다. 영상 화질 평가방법은 폐야의 미세구조, 진단영역의 넓음, air-fluid 경 계면의 명확 유무, 환자 회전유무, 심장음영과 횡격막의 선명유무를 기준으로 하였으며, 영상의학과 전문의 2 명, 호흡기내과 전공의 2 명이 blind test로 평가하였다. 환자 안정성 및 방사선 검사의 효율성 평가는 환자 position의 안정성, 환자 상태 확인 등의 기준으로 일반촬영 5 년 이상 경력의 방사선사 15 명이 5 점 척도로 
평가를 하였고, 통계 분석은 Paired T-test로 분석하였다. Chest decubitus 촬영 시 $\mathrm{AP}$ 와 PA자세에 따른 검사의 유용성을 비교 분석한 결과 영상의 화질에서 $\mathrm{AP}$ 와 $\mathrm{PA}$ 자세는 큰 차이가 없었던 반면, 환자의 안정 성 및 방사선사의 검사 효율성에 있어 $\mathrm{PA}$ 자세에 비해 $\mathrm{AP}$ 자세의 평가 점수가 높게 나타났다. 이에 특별히 $\mathrm{PA}$ 자세가 요구되지 않는다면 $\mathrm{AP}$ 자세로 검사하여도 무방할 것으로 사료된다.

중심단어: 흉부측와위, 전후방향 자세, 후전방향 자세

\section{I. 서 론}

단순 흥부방사선영상(simple chest radiography, CXR) 은 흥부의 방사선학적 진단에 대한 전반적인 내용을 파악할 수 있으며 적은 비용으로 추적관찰이 가능하 여 임상적으로 널리 이용되고 있는 흉부 질환 검사방 법이다. 검사의 기본적인 내용은 환자의 체위, $\mathrm{X}$ 선속 의 진행방향, 호흡상태, 관전압, 노출시간, 환자 상태 등에 따라 관찰부위 및 검사방법이 다양하며 이 중 가 장 일반적으로 사용되는 검사방법은 흥부 정면영상 (Chest PA)이다.

향부의 정면영상에서는 종격동, 기도질환, 폐혈관 및 폐결절성 음영, 심장음영 등을 관찰할 수 있으며 일반적인 검사방법에서 관전압을 환자의 체격보다 약 간 높여서 검사해야 하는 경우는 심장 및 대동맥 질환, 종격동 질환, 기관지 협착, 폐암 등이며 관전압을 낮추 어야 하는 질환은 폐기종, 기흉, 천식 등이다 ${ }^{[1]}$.

정상적인 흉부방사선영상의 방사선학적 소견에서 여러 가지 해부학적 형태와 음영의 대조도 구분이 반 드시 필요하며 특히 정상적인 폐는 공기로 채워져 있 어 대부분 방사투과성(radiolucent)을 보인다 ${ }^{[2]}$. 일반적 으로 폐문(lung hilum)으로부터 말초부위로 향하는 나 뭇가지 모양의 혈관영상인 페음영(lung marking)이 잘 나타나는 영상이 진단에 유리하게 작용하는데 이러한 폐음영은 기관이나 기관지는 포함하지 않은 영상이다 ${ }^{[3]}$. 흉부 질환의 방사선학적 유형 또한 중요하게 작용 하는데 음영의 증가 질환과 감소 질환을 구별하고 폐 포와 기관지를 제외한 조직에서 발생되는 간질성 폐 질환(interstitial lung disease)에 대한 특성도 고려되어야 한다.

따라서 기본적인 흥부영상의 임상적 소견을 객관화
할 때는 다음의 사항을 고려해야 하는데 즉. 정상적으 로 나타날 수 없는 음영이 나타나는 경우, 정상적으로 보여야 할 음영이 보이지 않는 경우, 특정 장기나 구 조물의 크기 및 위치 변화 등에 대한 세심한 관찰 등 이 요구된다.

측와위촬영 (Chest lateral decubitus view)은 늑막강내 의 액체나 늑막삼출(pleural effusion)을 나타내는데 사 용되며 흥부전후촬영으로는 늑막강내에 액체가 최소 한 300cc는 있어야 유소견을 보이나, 측와위촬영으로 선 소량(50cc)의 늑막삼출도 알아낼 수 있는 검사이며, 단순한 늑막유착과의 감별 진단에도 사용되는 유용한 검사이다 ${ }^{[4]}[\mathrm{Fig}$ 1.].

chest lateral decubitus 촬영시 일반적으로 PA Position 검사를 시행하여 왔으나, 응급 환자나 몸이 불편한 환 자의 검사에 있어 PA Position를 취하지 못하는 경우가 종종 발생하며 현재 많은 병원에서 Chest lateral decubitus 검사를 AP Position 검사와 PA Position 검사 를 전체적인 검사 상황에 알맞게 시행해 오고 있었다. 이에 본 연구에서는 동일 환자의 AP Position 검사와 PA Position 검사를 비교하여 영상화질, 환자의 안전성 및 방사선 검사 효율성을 분석하고 두 검사간의 유용 성을 알아보고자 하였다.

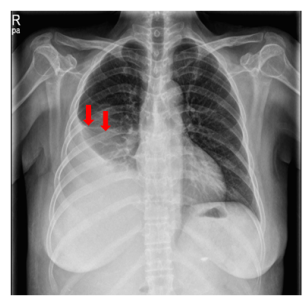

a) PA

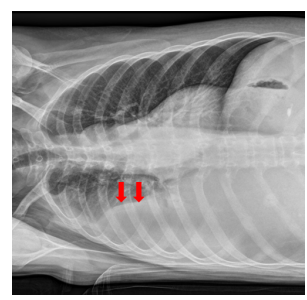

b) Decubitus
Fig. 1. Stand PA \& Decubitus PA Image 


\section{II. 대상 및 방법}

\section{1. 연구대상}

본원에 내원하거나 방문한 환자 중 2011.10.1 2012.7.30까지 늑막염 또는 기흉으로 의심되거나 진단 된 환자들 중 chest lateral decubitus 촬영을 시행한 30명 (남자20명 : 여자 10명)을 대상으로 환자의 동의를 얻 어 각각 $\mathrm{AP}$ 와 $\mathrm{PA}$ position으로 검사하였다.

\section{2. 검사장비 및 영상획득 조건}

1) 검사장비 : DR Philips Diagnost TH-VM

2) 촬영조건 : $102 \mathrm{kVp}, \mathrm{AEC}$ mode, grid ratio 12:1

3) FFD : $72 “(180 \mathrm{~cm})$

4) 중심 X-선 : T-6 (견갑골 하단)

\section{3. 연구방법}

\section{1) 환자 AP Position}

AP Position은 Chest lateral decubitus position을 stand burky detector에 등을 최대한 밀착시키고[Fig . 2] 환자의 몸이 회전되지 않도록 하였고 중심 $\mathrm{X}^{-}$선 은 견갑골 하단, T-6번으로 평행입사 하였다[Fig.3].

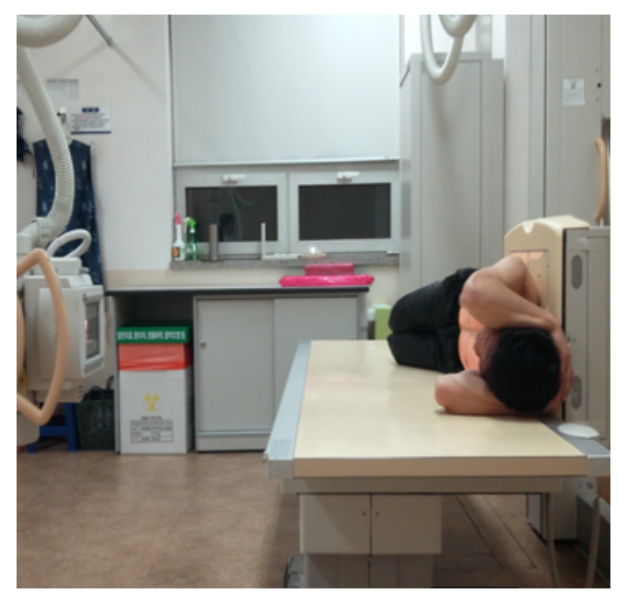

Fig. 2. AP Position

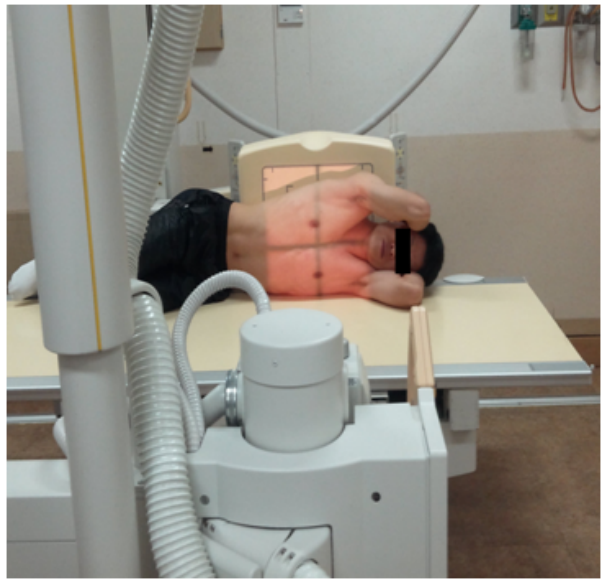

Fig. 3. AP Position

\section{2) 환자 PA Position}

PA Position은 Chest lateral decubitus position을 stand burky detector에 가슴을 최대한 밀착시키고[Fig. 4], 환 자의 몸이 회전되지 않도록 하였고 중심 X-선은 견갑 골 하단, T-6번으로 평행입사 하였다[Fig. 5].

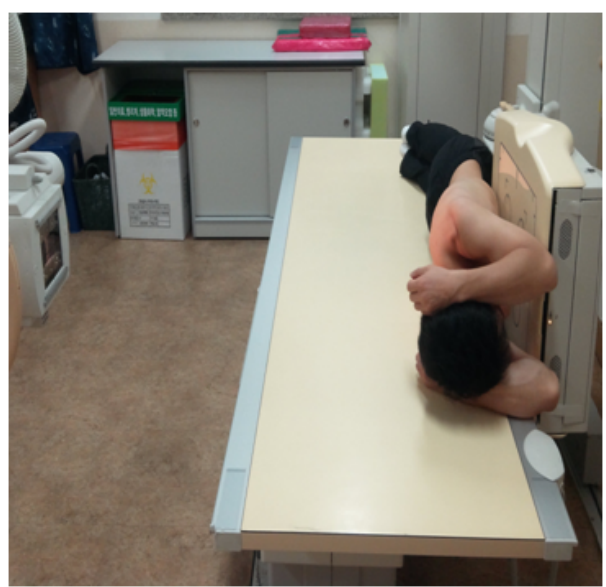

Fig. 4. PA Position 


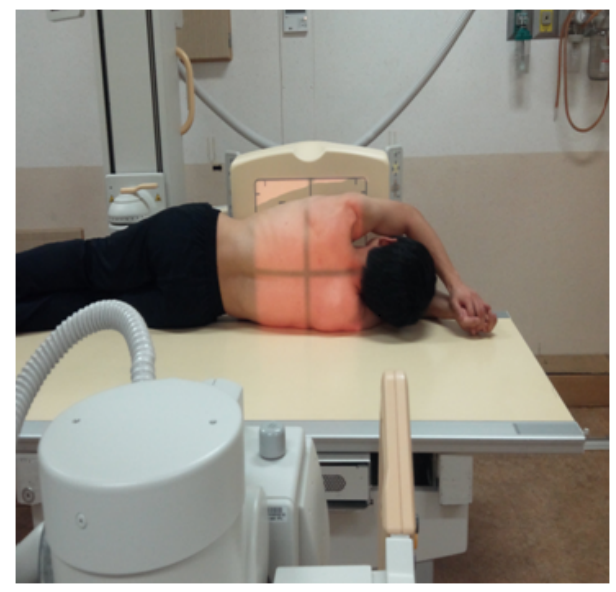

Fig. 5. PA Position

\section{4. 영상 평가기준 및 평가방법}

\section{1 영상화질 평가기준[Fig. 6] $]^{[5][6]}$}

1) 폐야의 미세구조는 잘 보이는가?

2) 진단영역은 넓은가?

3) Air-Fluid 경계면의 명확한가?

4) 환자 몸의 회전은 없는가?

5) 심장음영과 횡격막은 선명한가?

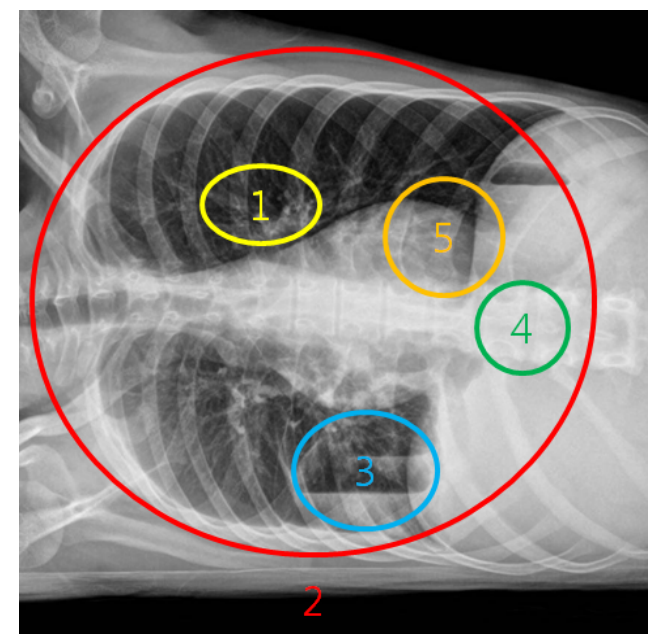

Fig. 6. Chest Lateral Decubitus Image

\section{1 영상화질 평가방법}

평가는 전문가 4 명 (영상의학과 전문의 2 명, 호흡기 내과 전공의 2 명)이 영상정보저장전달장치(PACS)에 저 장된 영상으로 모두 해상도 $2,048 \times 2,560$ 의 판독용 모 니터를 이용하여 Blind test를 실시하여 5점 척도 (Excellent:5점, Good:4점, Fair:3점, Moderate:2점, Bad:1 점)로 평가하였다 ${ }^{[7]}[$ Fig. 7][[Fig. 8].

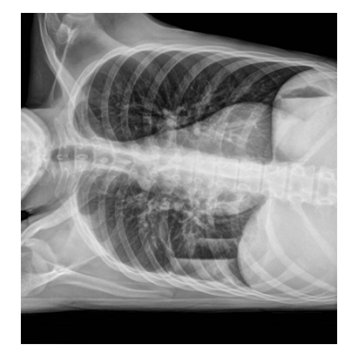

a) $A P$

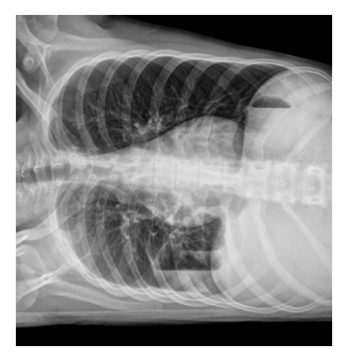

b) $P A$
Fig. 7. Little Effusion AP \& PA

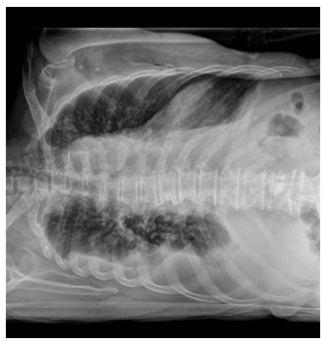

a) AP

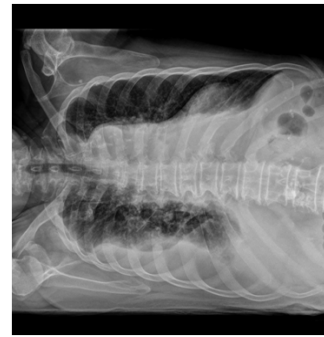

b) $P A$
Fig. 8. Lot of Effusion AP \& PA

\section{5. 환자 안전성 및 방사선 검사 효율성}

\section{1 환자 안전성 및 방사선 검사 효율성 평가기준}

1) 환자 Position은 안전한가?

2) 환자상태 확인은 어떠한가?

3) 방사선 검사 효율성은 어떠한가?

\section{2 환자 안전성 및 방사선 검사 효율성 평가방법}

평가는 일반촬영 임상 경력 5년 이상의 방사선사 15 명에게 $\mathrm{AP}$ position 검사와 $\mathrm{PA}$ position 검사의 두 검사 
방법을 평가기준에 맞게 설문조사 하였다.

\section{6. 통계방법}

영상화질, 환자 안전성 및 방사선 검사 효율성에 대 한 결과는 통계프로그램(SPSS Ver. 19 for windows) 을 사용하여 대응 t 검정 (paired t-test)을 시행하였 다. 통계학적 유의성은 $\mathrm{p}<0.05$ 를 기준으로 하였다.

\section{III. 결 과}

영상의 화질 분석결과는 폐야의 미세구조 AP 4.69 점, $\mathrm{PA} 4.73$ 점, 진단영역의 넓음 $\mathrm{AP}$ 4.58점, $\mathrm{PA} 4.79$ 점, air-fluid 경계면의 명확 유무 AP 4.65점, PA 4.71점, 환 자 회전유무 $\mathrm{AP}$ 4.66점, $\mathrm{PA}$ 4.35점, 심장음영과 횡격막 의 선명유무 $\mathrm{AP}$ 4.72점, $\mathrm{PA}$ 4.74점으로 측정되었으며, 영상의 화질 평가 부분에서 $\mathrm{AP}$ 와 $\mathrm{PA}$ 에서 큰 차이를 보이지 않았으며 평균치 또한 4.66점과 4.67점으로 근 소한 차이를 보였습니다. 그러나 환자 회전유무에서 $\mathrm{PA}$ 보다 AP가 다른 항목 수치보다 조금 더 높은 차이 를 보였습니다[Fig. 9][Table 1.].

환자의 안정성 및 검사 효율성의 분석결과는 환자 position 안정성 $\mathrm{AP} 5$ 점, $\mathrm{PA} 3.47$ 점, 환자 상태 확인 $\mathrm{AP}$ 4.8점, $\mathrm{PA} 1.73$ 점, 방사선사의 편이성 $\mathrm{AP} 5$ 점, $\mathrm{PA} 3.47$ 점으로 측정되었으며, 환자의 안정성, 검사 효율성 전 체 평균 점수는 $\mathrm{AP}$ 4.93점, $\mathrm{PA}$ 2.89점이었다[Fig. 10][Table 2.].

Table 1. Value results of image quality

\begin{tabular}{|c|c|c|c|c|}
\hline & 평가 항목 & AP & $\mathrm{PA}$ & $p$-value \\
\hline 1 & 폐야의 미세구조 & 4.69 & 4.73 & \multirow{6}{*}{$p>0.05$} \\
\hline 2 & 진단영역의 넓음 & 4.58 & 4.79 & \\
\hline 3 & Air-Fluid 경계면의 명확유무 & 4.65 & 4.71 & \\
\hline 4 & 환자 회전유무 & 4.66 & 4.35 & \\
\hline \multirow[t]{2}{*}{5} & 심장음영과 횡격막의 선명유무 & 4.72 & 4.74 & \\
\hline & 평 균 & 4.66 & 4.67 & \\
\hline
\end{tabular}

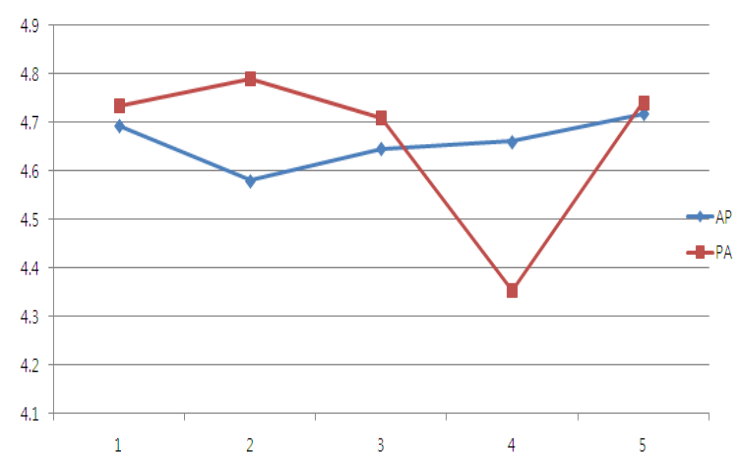

Fig. 9. Value results of image quality

Table 2. Value results of X-ray efficiency and Patient safety

\begin{tabular}{|c|c|c|c|c|}
\hline & 평가 항목 & $A P$ & PA & p-value \\
\hline 1 & 환자 Position 안정성 & 4.69 & 4.73 & \multirow{4}{*}{$p<0.05$} \\
\hline 2 & 환자 상태 확인 & 4.58 & 4.79 & \\
\hline \multirow[t]{2}{*}{3} & 방사선 검사의 효율성 & 4.65 & 4.71 & \\
\hline & 평 균 & 4.66 & 4.67 & \\
\hline
\end{tabular}

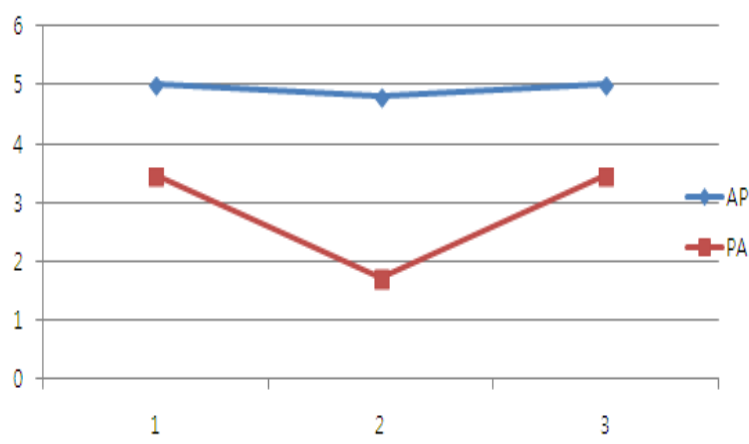

Fig. 10. Value results of X-ray efficiency and Patient safety

\section{IV. 고 찰}

단순 흥부 방사선영상(simple chest radiography)에 나 타나는 진단적 정보는 입체적인 정보로써 폐자체가 가지고 있는 공기의 음영이 일종의 조영제 역할을 하 여 병소의 발견에 도움을 준다. 또 폐음영(lung marking)이 잘 나타나고 폐첨이 넓게 나타난 영상은 미 세한 병변의 발견에 유리하다. 현재 우리나라의 경우 에는 어떠한 질환으로 병원에 입원하는 경우에는 거 의 예외 없이 단순흉부촬영을 하고 있는 실정이며 이 
는 결핵 등 주변 사람들에게 감염의 우려가 있는 질환 을 사전에 진단하여 집단감염 등을 예방하는 효과가 있다.

Costophrenic angle (CP angle)은 늑골흉막과 횡격흉 막의 연결부위를 말하는데 이곳의 둔화(blunting)는 흥 막삼출액(pleural effusion) 등에 의해 나타난다. 흥막액 은 여러 가지 원인으로 생성되며 성분에 따라 여출액 (transduate)과 삼출액(exudate)으로 나뉘고 혈액이나 농, 유미즙(chyle) 등을 함유하는데 일반적으로 선 자세에 서는 후늑횡격막 함요(posterior costophrenic recess)에 축적되는 경우가 많담]

영상을 평가함에 있어서 영상의학과 전문의는 영상 의 전체적인 면을 보고 영상의 평가점수를 주었고 호 흡기내과 전공의는 보고자 하는 흉막삼출액(pleural effusion)이 잘 보이는데 더 많은 평가점수를 주는 경향 이 있었다. 하지만 이는 전체적인 점수로 볼 때 그 차 이는 미미한 것이었으며 궁극적으로 보고자 하는 평 가에 있어선는 비슷한 결과를 나타냈다.

검사 소요시간으로 보면, PA Position 검사에서는 정 상적인 환자에서 시행했을 때, 약 5 7분 정도 소요되 었으며 방사선사 단독으로 검사가 가능하였지만 몸이 불편하거나 응급환자에서 검사를 시행하였을 때에는 10 15분 이상이 소요되었으며 방사선사 단독으로는 검사가 불가능하였다. 이 때 검사를 시행한 환자들은 Lateral Decubitus 자세를 취하는 데 많은 불편함을 느 끼고 고통을 호소하기도 하였다. 본 연구는 $\mathrm{AP}$ Position 검사 시 검사 자체는 방사선사 단독으로 수행 되며 검사 소요시간 역시 정상 환자를 검사했을 때와 비슷한 5 7분 정도가 소요되었다. 뿐만 아니라 $\mathrm{AP}$ Position 검사법은 환자가 검사 중 불편함이나 고통을 호소하는 경우가 드물었다.

\section{$\mathrm{V}$. 결 론}

이상의 연구를 종합해 보면, Chest lateral decubitus 촬영 시 $\mathrm{AP}$ Position과 PA Position 자세에 따른 검사의 유용성을 비교 분석한 결과 영상의 화질에서는 전체 적으로 $\mathrm{AP}$ 와 $\mathrm{PA}$ 에서 큰 차이를 보이지 않았으며, 환

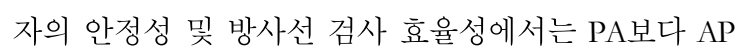
에서 평가 점수가 높게 나타났습니다.
일반적으로 검사해 온 PA Position이 요구되지 않는 다면 영상의 화질 면에서 $\mathrm{AP}$ 와 $\mathrm{PA}$ 가 큰 차이를 보이 지 않았고, 환자 안정성 및 방사선 검사 효율성에서 높은 평가를 받은 AP Position 또한 유용할 것이며, 신 속한 검사가 요구되는 응급실 일반촬영 업무에 있어 서 Both Chest Lateral Decubitus 처방 시 AP와 PA로 검 사하여도 무방할 것으로 사료됩니다.

\section{참고문헌}

[1] 김함겸 : 영상진단학, 대학서림, 215-216, 1997

[2] 양승오, 한창열 : 최신영상의학, 한미의학, $92,123,575,2005$

[3] 지제근 : 의학용어 큰사전, 아카데미아, 1042, 2004.

[4] 김석찬, Korean Journal of Medicine, Vol. 81, No. 1, pp.143-149, 2011.

[5] Han KY., Cho SG., Radiologic examination at lateral decubitus position for reducing the variability of cup inclination, $\mathrm{J}$ Korean Orthop Assoc, Vol. 44, pp. 409-413, 2009.

[6] Crowninshield RD, Maloney WJ, Wentz DH, Humphrey SM, Blanchard CR. Biomechanics of large femoral heads: what they do and don't do. Clin Orthop Relat Res, Vol. 429, pp.102-107, 2004.

[7] 강세식, 고성진, 지연상 등 : TEXTBOOK of Radiographic Positioning AND Clinicla Diagnosis, Chung-ku 출판사, 622-624, 2002

[8] 강형근, 김 홍, 김건일 외 : 임상 진단 방사선학, Vol. 27, 2000. 